\title{
ON THE MINERAL CONSTITUENTS OF CINNAMON AND CASSIA.
}

\author{
By O. HeheER, F.C.S.
}

Read before the Society of Public Analysts, on 19th Nov., 1879.

THE discrimination between ground cinnamon (Cinnamomum Zeylanicum) and cassia (C. Lignea and C. Vera) is a matter of some importance, but of considerable difficulty. These spices are imported into this country in very large quantities. Thus during the first forty-three weeks of this year 18,002 packages (of 56-lbs. each) of C. lignea, against 13,212 packages of cinnamon (each weighing about $\frac{3}{4}$-cwt.), and during the same period of last year, 45,433 packages of cassia and 13,489 of cinnamon were imported. The wholesale prices of cinnamon fluctuate between $6 \mathrm{~d}$. and $4 \mathrm{~s}$. $3 \mathrm{~d}$. per lb., whilst cassia barely reaches $6 \mathrm{~d}$. Considering now the extreme similarity between these barks, both botanical and structural, not a little inducement exists to substitute the cheaper for, or mix it with the more valuable spice, and it is a fact, that notwithstanding the large amount of cassia imported, it is almost impossible to obtain it under its proper name at retail establishments. I am informed that cinnamon sticks are never ground, but always sold in their whole state, only cinnamon chips and cassia being powdered. Much cassia, no doubt, is used by distillers of essential oils, manufacturers of mixed spice and of curry powder, but it cannot be doubted that much of it finds its way into the consumer's hands under a name to which it has no valid claim. However this may be, it is important to Public Analysts that they should be in possession of means to discriminate between the two kinds of bark.

The only test which, as far as I am aware, has been in use, is that founded upon the alleged difference in the behaviour of the decoctions towards iodine. Thus Flückiger and Hanbury direct in their Pharmacographia to "make a decoction of 
powdered cinnamon of known genuineness, and one of similar strength of the suspected powder. When cool and strained test a fluid ounce of each with one or two drops of tincture of iodine. A decoction of cinnamon is but little affected, but in that of cassia a deep blue-black tint is immediately produced." But, considering that both cassia and cinnamon contain much starch-as shown by the microscope-it seems a priori improbable that cassia starch should act normally towards iodine, whilst that of cinnamon refuses to do so. The different amount of tannin would certainly not explain the distinction as has been suggested by Pereira, as both cassia and cinnamon are rich in tannic acid. But the fact is that decoctions of both cassia and the cheaper kinds of genuine cinnamon turn blue with iodine. A few drops of iodine are first decolorized by the solutions, but a point is readily reached when the blue colour permanently makes its appearance, modified, of course, by the yellow colour of the decoction. The finest samples of cinnamon do not react much with iodine, probably because, on account of their immaturity, they contain little real starch. The iodine test is therefore of very questionable value, and genuine cinnamon might by it be condemned as adulterated. It may be admitted that in the case of cassia the reaction is obtained more readily than with cinnamon.

To find, if possible, some real difference between the two kinds of bark, I examined their mineral constituents, believing that the more woody bark, cassia, would contain a larger amount of salts of lime and magnesia than the delicate membranous cinnamon. The following analyses show, however, that this supposition was not entirely substantiated. All analyses were made upon the ash obtained at the lowest possible temperature (below visible red heat), but not recarbonated, that is to say, precisely as they would result in an ordinary analysis.

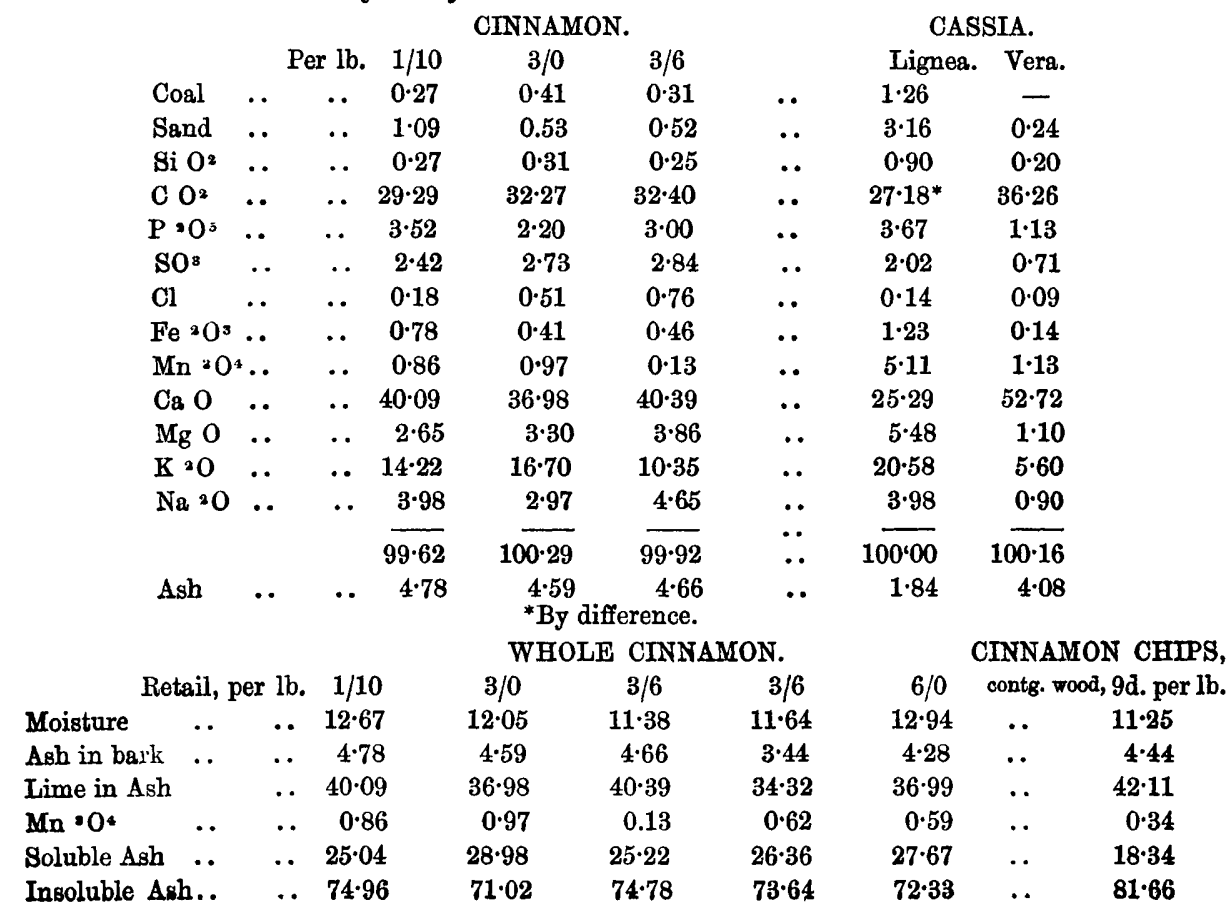




\begin{tabular}{|c|c|c|c|c|c|c|c|}
\hline \multirow[b]{3}{*}{ Moisture $\quad .}$. & \multicolumn{4}{|c|}{ CASSIA LIGNEA. } & & CASSI & \multirow[t]{2}{*}{ VERA. } \\
\hline & & & Whole. & Ground. & & & \\
\hline & . & $14 \cdot 22$ & $11 \cdot 88$ & $11 \cdot 05$ & . & $10 \cdot 37$ & $11 \cdot 36$ \\
\hline Ash in Bark .. & . & $1 \cdot 84$ & $2 \cdot 54$ & $2 \cdot 55$ & .. & $4 \cdot 08$ & $4 \cdot 85$ \\
\hline Lime in Ash.. & . & $25 \cdot 29$ & $34 \cdot 49$ & $28 \cdot 63$ & .. & $52 \cdot 72$ & $43 \cdot 40$ \\
\hline $\mathrm{Mn}^{3} \mathrm{O}^{4} \quad \ldots$ & . & 5.11 & 4.94 & 3.55 & .. & $1 \cdot 13$ & 1.53 \\
\hline Soluble Ash .. & . & $40 \cdot 58$ & $26 \cdot 78$ & $30 \cdot 91$ & .. & $8 \cdot 36$ & $15 \cdot 89$ \\
\hline Insoluble $\quad$. & .. & $59 \cdot 42$ & $73 \cdot 22$ & $69 \cdot 09$ & .. & $91 \cdot 64$ & $84 \cdot 11$ \\
\hline
\end{tabular}

Examining these figures it appears-First, that the proportion of ash in cinnamon fluctuates between comparatively narrow limits. Cassia vera contains an amount equal to that of cinnamon, but C. lignea yields much less. Secondly, that the amount of ash soluble in water is about one quarter of cinnamon ash, less in C. vera, more in C. lignea. Thirdly, that cinnamon ash contains less than one per cent. of oxide of manganese, C. vera upwards of one per cent. C. lignea far more, up to five per cent. This is indeed the most noteworthy feature brought out by the analyses. The amount of manganese has a direct influence upon the colour of the ashes. Thus all cinnamon ashes are white, or nearly so, those of both descriptions of cassia grey or brown, and the latter, when heated with hydrochloric acid, yield an abundance of chlorine gas. Thus the amount of manganese serves to distinguish cinnamon from $\mathrm{C}$. lignea with a high degree of probability, and even a comparatively moderate admixture of the latter would thus be rendered evident in the former. The manganese is most readily separated from the ash by means of bromine after the phosphate of iron has been precipitated by acetate of soda.

The difference between cinnamon and cassia vera is not so marked, but the low proportion of soluble ash in this will be a point worthy of notice. But $\mathrm{C}$. vera is only imported to a very small extent, and it is as an adulterant or substitute, of far less importance than the cassia commonly so-called, namely C. lignea. It is, moreover, so mucilaginous that when heated with water it yields a glairy or ropy decoction.

All of the samples, the analyses of which are reported above, were of undoubted purity, and many of them were kindly furnished me by Messrs. J. Travers and Son, to whom I am much indebted. My thanks are also due to Mr. E. Riley for having assisted me in carrying out the investigation.

Dr. Dupré asked Mr. Hehner whether he had any information as to the places where the cinnamon and cassia came from. It might be that this remarkable amount of manganese was not always found; was there reason to suppose that it was really a characteristic of cassia, or that it was due to a local peculiarity of the district.

Mr. Stewart asked if Mr. Hehner had made any determinations of the quantity of iodine added in each case; it seemed to act much more rapidly with cassia than with cinnamon.

Mr. Hehner, replying to Dr. Dupré, said that he had had one of the samples of cassia lignea for two years, two other samples were quite recent, two cheap cinnamons were recent also, and they gave an ash very rich in manganese, which no doubt proved that they consisted of cassia. He had no doubt that by far the largest amount of ground cinnamon sold was really cassia. In reply to Mr. Stewart, he said cinnamon decoctions required, as a rule, a very much larger quantity of iodine. The test as given in different books was really contradictory. Flückiger and Hanbury say : first add one or 
two drops, and "a deep blue-black tint is immediately produced," and a few lines further on they say, "But the colour quickly disappears and becomes permanent only after much of the test has been added." No doubt there is a little more starch in cassia than in cinnamon. 